\title{
ECONOMIC GEOLOGY
}

Vol. XXIII MARCH-APRIL, I928 No. 2

\section{DIRECTIONS OF PROGRESS IN ECONOMIC GEOLOGY ${ }^{1}$}

\section{F. L. RANSOME}

THE subject chosen for my address this morning is of rather general character and one that should permit a retiring president to exercise his privilege of indulging in retrospective as well as in prospective views and of expressing ideas which, although possessing little novelty, may, nevertheless, be worthy of consideration. My own work in economic geology has been mainly with ore deposits, and if in the present address that particular aspect of geology seems to receive disproportionate attention, this is due to the limitations of my own experience and not to any desire to minimize the significance of geology in relation to the occurrence of oil, coal and other non-metallic resources and to problems of engineering in connection with the construction of dams and reservoirs, the driving of tunnels, and other projects in which the character and structure of the rocks and the geologic history of the region may be of fundamental importance.

As we look back over the past fifteen or twenty years, it does not appear that we have made such progress as will mark this period as particularly noteworthy in the history of our science. The recognition of the predominant part played by thermal water in ore deposition; the outlining of the processes of metasomatism; the perception of the close connection between ore genesis and igneous intrusion; the discernment of the general zonal arrange-

1 Presidential address delivered before the Society of Economic Geologists, Cleveland meeting, December 30, 1927. 
ment of ores in relation to igneous intrusive masses; the discovery that the minerals of sulphide ore bodies have usually formed in a more or less orderly sequence; and finally, the arrival at a fairly satisfactory state of knowledge concerning supergene enrichment, especially of copper and silver ores-these all date from an earlier period than that to which I have just referred.

The general tendency during late years has undoubtedly been to regard ore deposits as more and more closely linked in origin with the process of magnetic differentiation in igneous rocks, and there are brilliant enthusiasts among us who decline to see any difference between a vein and a dike. Perhaps there is no absolute division between the two, for, after all, classification is a human device and we are frequently impelled to draw lines where nature has left more or less shadowy zones of gradation. Nevertheless, at the risk of being considered old-fashioned, I wish to express adherence to the view that most ore deposits are the work of mobile aqueous solutions, basing this conclusion particularly upon experience with the gold ores of Cripple Creek; the leadsilver replacement deposits of the Cœur d'Alene district, in Idaho; the veins of Butte; the great displacement copper deposits of Bisbee and Jerome, Arizona; the disseminated copper deposits of the southwestern United States; the gold deposits of California, of Oatman, Arizona, and of Goldfield, Nevada; the quicksilver deposits in various parts of the west. To one who holds such a view, the introduction of the terms " veindike" and the equally uncouth " magmation" is naturally not to be considered as a milestone in the progress of economic geology.

Precisely as was the case with older views, the modern protagonists of the magmatic origin of ores have sought to reduce the formation of all ore deposits to the operation of one major process. They hold that where sulphide ore is present, there must be present also, whether visible or not, the intrusive rock that is representative of the magma whence the ores came. Possibly they are right but their evidence is unconvincing. Not to speak of many deposits of lead and zinc sulphides and some copper ores that appear to lack any obvious genetic relationship to intrusive 
rocks, some of the Tertiary gold-silver veins in lava flows are not clearly dependent upon igneous intrusions. They possess rather characteristically the disconcerting habit of disappearing at moderate depths with little to indicate downward continuity with a deep magmatic source. Examples that come to mind are the veins of Oatman, Arizona and of Mogollon, New Mexico. Even where igneous rocks are visible we frequently find it difficult to agree as to which rock has a genetic relationship with the ore. In the Jerome district, Arizona, for instance, some geologists have considered the deposition of the pre-Cambrian copper ores to be related to the intrusion of the Bradshaw granite, the nearest exposure of which occurs several miles away; others have concluded that the so-called Cleopatra porphyry represents the magma from which the ores came. My own recent study of the district has led me in turn to the conclusion that the Cleopatra porphyry is in the main an ancient rhyolitic flow and that the intrusion of the augitic Verde diorite was probably the event most closely connected with ore deposition.

It is not implied in the statements just made that the hypothesis or theory that most sulphide ores are of direct magmatic origin is incorrect, but my thought is rather to suggest that something yet remains to be done to establish it on a sound basis as a generally inclusive explanation.

Among the distinct advances of recent years should be mentioned the accumulation of evidence of the zonal distribution of ores of particular metals around intrusive igneous masses. The idea itself is probably at least 75 years old but was revived during the early part of the present century by De Launay, in connection with the conception of metallogenetic provinces, and has been found applicable, in a broad way, by later investigators to the deposits of many regions, in all parts of the world. Recent papers by W. H. Emmons, ${ }^{2}$ setting forth evidence for the zonal grouping of ore deposits and proposing a classification of deposits, based upon position with reference to the related intrusive mass, are particularly noteworthy.

2 Emmons, W. H., "Relations of Metalliferous Lode Systems to Igneous Intrusions." Trans. A. I. M. M. E., vol. 74, pp. 29-70, 1927. 
The work of Augustus Locke and his assistants, on the interpretation of gossans, also deserves notice as a courageous attempt to solve a difficult problem of great practical importance. There is a considerable element of empiricism in their work and the interpretation of oxidized outcrops in terms of original sulphides appears at present to demand special and long experience that few geologists have acquired. Nevertheless some success has been achieved and there is ground for hoping that further progress may be made in this hitherto neglected field. Locke, Blanchard, Boswell, Kingsbury, and others who have collaborated in this work, deserve the credit of being pioneers in a promising line of investigation.

Certain advances in the technique or methods of economic geology should also be referred to in any general summary of progress. Various electrical methods of prospecting have in recent years gained recognition as being useful under certain conditions and have triumphantly emerged from a status of supposed close relationship with that curious evidence of human credulity, the forked rod of hazel. This application of physics to practical geology is still young but has demonstrated its capacity not only to detect the presence of bodies of metallic sulphides but also to work out geological structure and thus to become an aid in the exploration for oil and other non-metallic substances. Similar comment might be made with reference to the torsion balance and seismograph, now used in prospecting for oil, especially where it occurs in the vicinity of salt domes.

In the same category of advancement in technique should be noted also the development and application of what has been called micro-paleontology to the identification of strata penetrated by the drill, whereby use is made of foraminifera and other minute organisms that can be recognized in the drill-sludge.

Having briefly referred to some of the recent advances in economic geology, I come now to the question-Why has progress during recent years not been more rapid?

The principal reason, as I see it, is the lack of fundamental chemical and physical data. We have been accumulating a vast 
store of observations on the results of geologic processes and have been indulging in more or less intelligent guessing as to the nature of the processes themselves, many of which have operated under conditions that must have been far removed from anything within the range of our own experience. We argue on the one side, for example, that the silica of certain quartz veins was deposited from mobile fluid solutions, and on the other side that it must have shouldered its way into its present position as a stiff or gelatinous magma. We may perhaps advocate a compromise view, namely, that although originally deposited from thin solution, the silica passed through a gelatinous or stiff condition, with possibly various movements and stages of crystallization before its final solidification as quartz. We may fancy that we have evidence for one or other of these views, but I believe that our opinions, except perhaps for veins of one or two characteristic types, are largely conjectural. As a matter of fact, we do not really know how silica, water, and metallic sulphides, or their constituents, behave at the temperatures and under the pressure that must have prevailed during the formation of many ore-bodies.

That the behavior of silica has great practical importance is illustrated by a problem that is now pressing for solution in the Bisbee district, Arizona. Most of the known ore bodies in that district appear to have a fairly close connection with masses of quartz that have replaced the Paleozoic limestones irregularly and outcrop at the present surface. Similar, if not identical, masses of quartz occur in outlying parts of the district, some miles from any known ore. Is there ore within practical mining distance beneath them? Do they represent the devious migration of siliceous solutions beyond the region of ore deposition? Have they any connection whatever with ore deposition? The future of a great copper district depends upon the answers to these questions. The geologist may have an opinion about this problem but he cannot answer the questions with the sureness and precision of real knowledge. In the meantime, extensive underground exploration is in progress in an attempt to settle the problem in a practical but expensive way. 
To take another example, we have discussed for many years the question of the origin of the nickel-copper deposits of Sudbury and are not yet agreed whether they have merely settled from the associated norite magma by a more or less hypothetical process of differentiation, have been deposited by hot or thermal water, or by some combination of the two processes.

Again, leaving for the moment the subject of ore deposits, we, as economic geologists or as geological engineers, are sometimes asked to determine whether a certain reservoir site will hold water behind a dam 300 or 400 feet high. As far as I know, there are no experimental or quantitative data on record that will furnish a basis for answering this question. The geologist must make the best prediction that he can under the circumstances, perhaps aided by some knowledge of the behavior of reservoirs previously filled in similar rocks.

Are we to conclude that it is impracticable to obtain more definite information to help us to answer these and other questions in economic geology, or must we continue to observe and record the end results of geological processes and remain content to guess at the nature of the processes themselves? I firmly believe that if real progress is to be made in the theory of ore deposition we must turn our attention more and more to the task of obtaining, in collaboration with chemists and physicists, a larger body of fundamental information than we now possess.

The recent papers by Boydell, ${ }^{3}$ in which he discusses critically the probable action of colloidal solutions in ore deposition and the physical chemistry of metasomatism, are steps in the right direction, but we require more experimental work on these same problems.

Experimental work of the kind needed is beyond the resources of most individual investigators and demands also such continuity of effort as cannot be confidently expected of a single worker, for whom favorable working conditions may so easily be de-

3. Boydell, H. C., "The Rôle of Colloidal Solutions in the Formation of Mineral Deposits,". Inst. Min. and Met. (London), Dec., 1924. "Discussion of Metasomatism," Econ. Geol., vol. 21, pp. 1-55, 1926. "Operative Causes in Ore Deposition," Inst. Min. and Met. (London), Oct. 27, 1927 (advance copy). 
stroyed by an unexpected turn of events. It might, however, be undertaken by an organization created and endowed for the purpose or by such an existing organization as the Geophysical Laboratory of the Carnegie Institution of Washington, which is not under political control and which consequently is not hampered by any necessity to produce real or apparent results before the next appropriation. To those who might object that such work would be a falling away from the ideals of pure science, it is only necessary to point out that scientific work loses nothing in spirit or method merely because the results sought are known to have direct and immediate utility. The old notion that a scientific investigation undertaken with prior knowledge that the results desired will be useful or beneficial must in some way be inferior to one in which the application of the results is as yet unknown, is a fallacy which was thoroughly discredited by the achievements of Pasteur.

Among the particular problems upon which light might be thrown by research from the physical and chemical side a few only will here be briefly mentioned. One of the first that comes to mind is that concerning the nature of the solutions that carry and deposit sulphide ores, if it be admitted that such ores are deposited from solution. From some old experimental work by Becker and Melville, from our knowledge of hot-spring waters, and from the metasomatic changes effected in the wall rock of veins, we generally accept the view that most veins carrying metallic sulphides have been deposited from alkali sulphide solutions. For the lead-zinc ores of the Ozark region, Siebenthal ${ }^{4}$ has argued for " alkaline-saline sulphureted waters," the metals being carried as bicarbonates and thrown down under conditions that permitted the escape of carbon dioxide. We need more definite information concerning the capacity of various possible natural solutions to carry ore constituents and concerning the chemistry of ore deposition. Some of this information at least could be supplied by experimental work.

4 Siebenthal, C. E., "Origin of the Zinc and Lead Deposits of the Joplin Region," U. S. Geol. Survey Bull. 606, p. 161, 1915 . 
Another problem for the geophysicist and geochemist, as. Lindgren ${ }^{5}$ has pointed out, is to explain the observed general succession in the deposition of the minerals in complex ores, the younger minerals not only following the older in more or less orderly sequence but also successively replacing them.

The question as to the behavior of silica in ore deposition has previously been mentioned. Our difficulties with silica, however, do not cease with the original deposition of the ores. In many gossans, such as occur above the great copper deposits at Bisbee and Jerome, Arizona, there appears to be more quartz than was present in the original ore. This raises the questions: To what extent is silica dissolved and redeposited during the oxidation of sulphide ore bodies, and what is the chemistry of the process? The answers to these questions have an important bearing upon the interpretation of the oxidized outcrops of ore deposits.

Certain lead deposits, particularly the great manta deposit at Los Lamentos, Mexico, show a remarkable concentration of wulfenite and vanadinite in the lower part of the oxidized zone. Is this a downward concentration of small quantities of molydenum and vanadium originally present in galena and, if so, why are these constituents concentrated near the level of underground water?

If most sulphide ore bodies are magmatic differentiation products from intrusive igneous rocks, it would appear that quickly chilled, glassy volcanic rocks should contain a larger proportion of the metals than do their plutonic equivalents. If this be true, have we not a suggestion for the origin of some deposits in Tertiary volcanic flows other than that of direct ascent from some hypothetical magmatic reservoir? So far as I am aware, no thorough investigation has been made to determine this point. Of course the quantities or proportions of metal involved would be extremely small and the work would require special analytical methods and a very large number of determinations.

Another question relates to the enrichment of sulphide ore deposits, particularly of copper deposits. Does the process take

5 Lindgren, W., "Magmas, Dikes and Veins," Trans. A. I. M. M. E., vol. 74, p. 89, 1927 . 
place only below the surface of underground water, or is it possible that in arid regions, where the supply of water from the surface is scanty, the surface of underground water lies deep, and sulphides are abundant, oxidation may cease some distance above the standing level of underground water and enrichment take place. The wide range and often irregular character of some of the enriched deposits in arid regions appear to hint at such a possibility.

The whole matter of metasomatic replacement, a process of which the results are obvious enough from the geological side, needs investigation from the chemical and physical side.

I might go on and cite other examples of the kinds of problems in which the cooperation of chemists and physicists is necessary if we are to solve them but such citation would probably be tiresome to many in my audience. Enough have been mentioned to indicate the general directions along which further progress in economic geology appears to lie. I shall now turn to another phase of my conveniently elastic subject.

In any consideration of the progress of economic geology it is appropriate on such an occasion as the present to inquire how our own Society can be effective for good.

I believe that one of the most important functions of the Society of Economic Geologists is to keep us in close touch with the scientific side of our profession, rather than with the industrial or merely economic side. In more or less intimate affiliation as many of us are with the development and exploitation of mineral resources, there is real danger that we drift away from the obligation to contribute to that branch of science which we are applying to utilitarian ends. It is from this point of view that comes the advantage, as it appears to me, of meeting, as we are now doing, with the geologists rather than with those who are interested primarily in the engineering and financial aspects of the mineral industries. Unless we remember that we are primarily scientific men we are likely to become content with the accomplishment of the particular job in hand and to lose sight of, or become apathetic towards, the broader consideration of our 
relation to scientific progress. We may possibly becorne mere users of the results obtained by others, without making any contributions of our own. We are drawing upon the scientific capital of geology and adding nothing to the principal. It should be a function of our Society to counteract this tendency and this it may do in various ways.

In the first place, it can demand such qualifications for membership that only those may be admitted to its ranks who have shown both the ability and the determination to contribute worthily to the literature of geology. Men who are not primarily geological investigators, who are concerned merely with the routine or industrial side of their profession, should not be regarded as prospective members, no matter how successful they may be in the usual sense of the word. In its choice of officers and representatives, the Society can make plain to all the ideals by which it sets most store.

In the second place, it can show by its prevalent affiliations with other organizations, by the character of its meetings, by the nature of its discussions, and by the tenor of its publications that it is essentially a scientific society and not a technical or industrial institution. This attitude can not fairly be ascribed to any unworthy spirit of exclusiveness but should properly be interpreted as loyal adherence to a particular purpose and ideal.

The maintenance of such an ideal and the diffusion of its spirit among our members should go far to bring about a more tolerant attitude on the part of mining companies and other business organizations toward the publication of the results of geological investigations conducted primarily for their own purposes. It must be admitted that occasionally a mining company, especially under the often unpredictable consequences of our unfortunate mining law, may have occasion to regret some particular publication; but it is believed that, on the whole, the publication of scientific results is more likely to be beneficial than injurious, even to individual mining companies. I am glad to say that at least some of the companies with which I have had some connection hold this broad view. 
Another advance towards which we as a society can probably contribute is that of coöperative geological work in mining districts. I am familiar with at least two districts in which the leading mining company maintains a strong geological staff whose members are likely to know more about the geology of neighboring mines than do those responsible for their operation. In others districts there are two or more independent geological staffs, each duplicating to some extent the work of the other and each in possession of some information that the other lacks. There may be no particular effort at secrecy yet there exists, nevertheless, a lack of complete mutual understanding. For example, in two adjoining mines that have recently occupied my attention, a particular group of rocks that is known in one mine by a certain name is entirely different in character and origin from the group known by the same name in the other mine. Furthermore, the geologists working in the two mines did not appear to be aware of this difference. Incidentally, the name is a binomial and recalled to me the remark ascribed to some historian with reference to the Holy Roman Empire, to the effect that it was neither "holy," nor " Roman," nor an " empire." It is to be hoped that the time will come when the companies in a mining district will combine to maintain an adequate geological department, whose members shall have access to all workings and whose results shall be available to all. There are of course obvious difficulties in the way of such a plan but they do not appear to be insurmountable. One step towards such an arrangement will be the recognition by mining companies that geologists as a class are men of high ideals with respect to truth, impartiality and duty. It is towards the attainment of such a standard that our Society can direct its influence.

It is natural that mining companies, who call in a geologist to advise them, should wish to have results as quickly as possible. The consequence is that, in many instances, far too little time is permitted for a thorough study. The visiting geologist is sometimes expected to accept in considerable part the facts as laid before him and to announce his decision. Probably in no branch 
of science is first-hand knowledge so important as in geology and, although the geological maps and structure, as worked out by the company's regular geologists or engineers, may prove to be highly useful in directing attention at once to particular features, they cannot safely be accepted as a basis for important decisions. It is not uncommon to find such work vitiated by some preconception, or defective in that it has failed to take account of certain facts that are displayed somewhere else in the region although perhaps not in the particular area or mine that is under consideration. Too close attention to some small area of ground with neglect of the general geology of the district or region as a whole, is a very common mistake on the part of mining geologists, due partly to defects in their own training and partly to inability on the part of their employers to recognize the desirability of a wider outlook.

As members of the Society of Economic Geologists, supported by the conviction that the Society as a whole stands for scientific research, we can all do our share towards improving the conditions just outlined, especially by convincing our clients of the desirability of granting sufficient time for a thorough study of the problems set before us. Both by communication and by example we can be influential in effecting improvement in the circumstances and character of economic geological work.

Finally, may I add a few comments on the subject of teaching economic geology; for, obviously, much of the progress of the future must come from those who are now passing through our universities.

If it is true that further progress must depend largely upon the fuller understanding and use of physical and chemical data, it is more than ever important that the coming geologist should be well equipped in physics and chemistry, which presupposes, of course, mathematics. He should be led, furthermore, to realize that no one can truly become an economic geologist without first becoming a good geologist-a fact that has sometimes been overlooked. The economic geologist, provided that his work is not limited to the purely scientific study of mineral deposits, may 
properly be regarded as a geologist who has accepted an additional responsibility, namely, that his conclusions be so sound that decisions involving large capital outlay may be based upon them. He has a double responsibility-first to science, and, second, to his clients. Although of course this should not be true, I cannot help feeling that sometimes "pure" geologists would be more careful in announcing their conclusions if they knew that these were to be tested forthwith by the expenditure of some thousands of dollars or that the success or failure of a great industrial enterprise depended upon their interpretation of some particular structure or the truth of their hypothesis of ore genesis.

Methods of teaching economic geology wifl, of course, vary with circumstances and with the personality of the instructor. Some confident spirits will be so sure of their own or adopted views that they will present these to their students with enthusiasm as the only true gospel. Others, more critical or less inspired, will have some doubts whether the whole truth is yet known. Shall these doubts be imparted to students or shall the teacher, for purposes of instruction, assume an appearance of that confidence which he can not feel?

The history of geology should, I think, make us cautious about accepting as final the theoretical views in vogue at the moment. By all means let us present to our students our own views as clearly as possible but let us also take pains to point out wherein these opinions differ from those held by other, and possibly most, economic geologists; and let us, furthermore, present as fairly as we can the theoretical ideas of those from whom we differ and whose ability and experience entitles them to a respectful hearing. The development of a questioning attitude in students, with the suggestion to them of the directions along which further investigation can be pursued, is believed to be more stimulating than the presentation of ostensibly complete and final theories. I believe, in short, in permitting our students to share our present doubts as well as to participate in our hopes for the future.

California Institute of Technology, Pasadena, Cal. 